Rabaska

Revue d'ethnologie de l'Amérique française

\title{
De la sauvegarde du patrimoine à la muséologie : Marius Barbeau
}

\section{Marilie Labonté}

Volume 13, 2015

Présence de Marius Barbeau : l'invention du terrain en Amérique

française. Autour d'un legs centenaire (1914-2014)

URI : https://id.erudit.org/iderudit/1033762ar

DOI : https://doi.org/10.7202/1033762ar

Aller au sommaire du numéro

Éditeur(s)

Société québécoise d'ethnologie

ISSN

1703-7433 (imprimé)

1916-7350 (numérique)

Découvrir la revue

Citer cet article

Labonté, M. (2015). De la sauvegarde du patrimoine à la muséologie : Marius

Barbeau. Rabaska, 13, 198-208. https://doi.org/10.7202/1033762ar d'utilisation que vous pouvez consulter en ligne.

https://apropos.erudit.org/fr/usagers/politique-dutilisation/ 


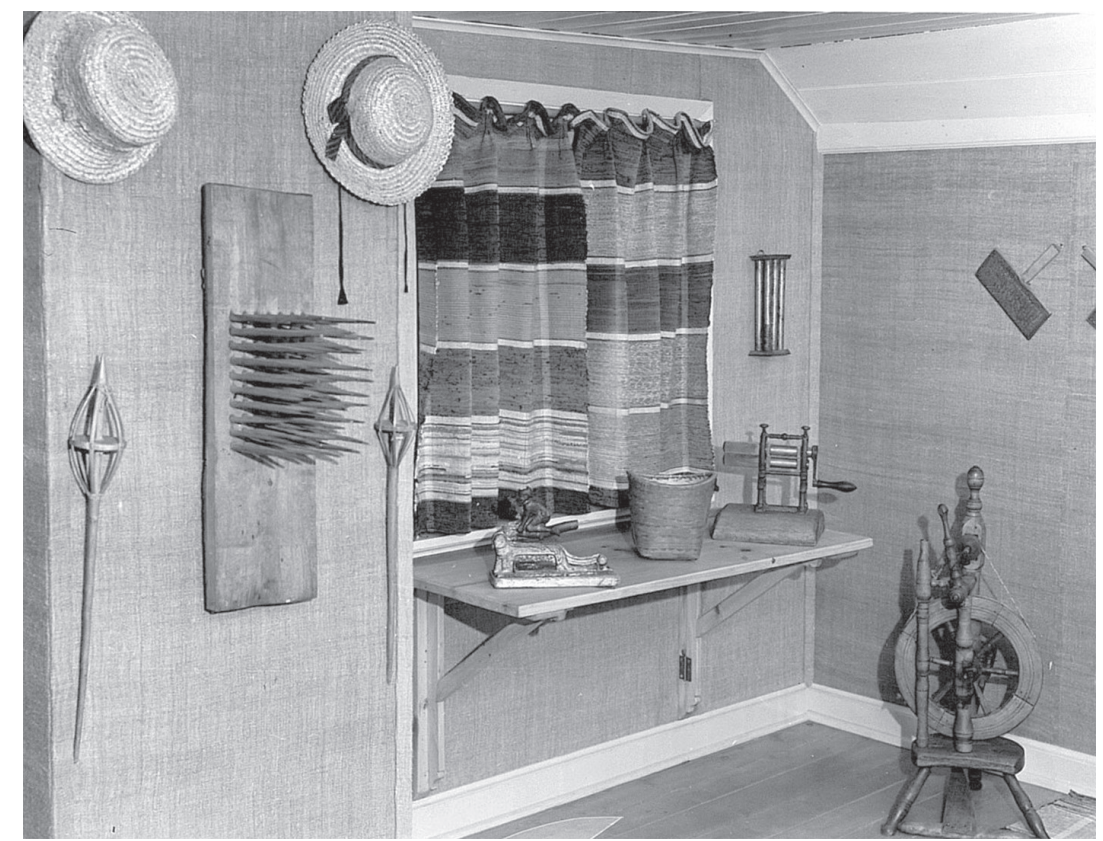

Intérieur de la maison Laurier de Saint-Lin (maison Robinette)

décorée et meublée par Marius Barbeau en 1940.

Source : Musée canadien de l'histoire no IMG2015-0229-0006-Dm.

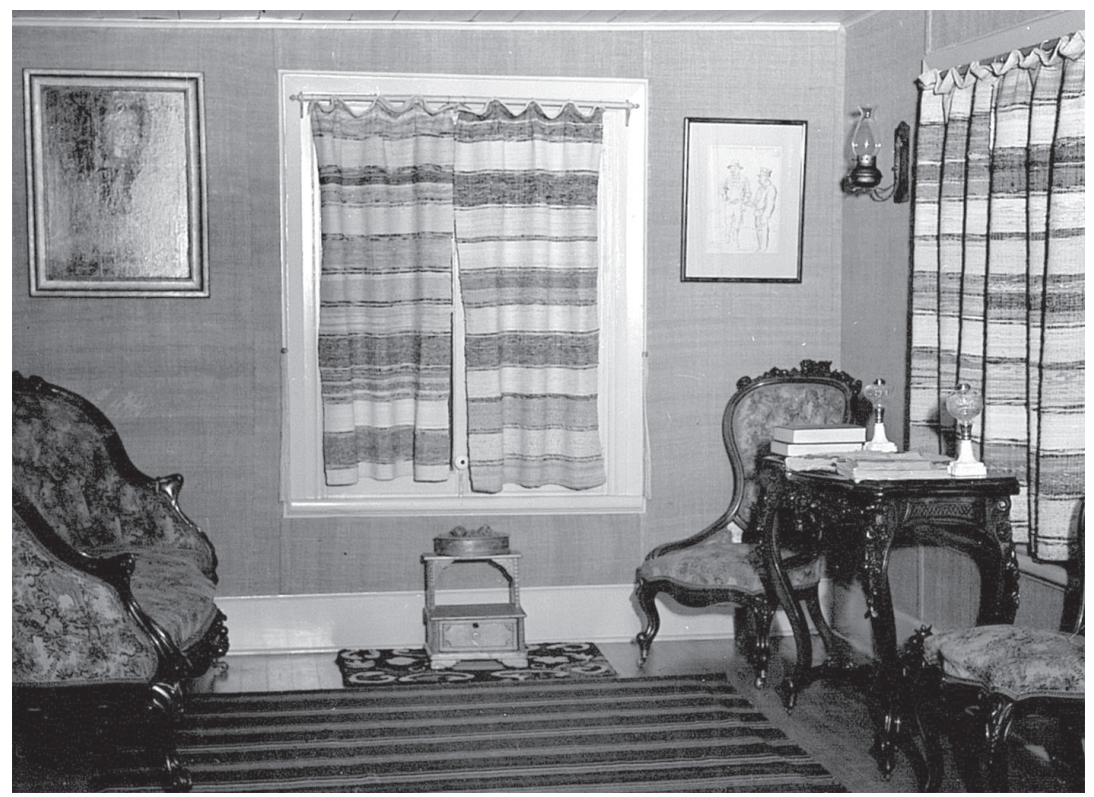

Intérieur de la maison Laurier de Saint-Lin (maison Robinette) décorée et meublée par Marius Barbeau en 1940.

Source : Musée canadien de l'histoire no IMG2015-0229-0004-Dm. 


\title{
Musées, muséologie, archives
}

\section{De la sauvegarde du patrimoine à la muséologie : Marius Barbeau}

\author{
MARILIE LABOnTÉ
}

Université du Québec à Montréal, Montréal

De nombreux écrits présentent Marius Barbeau sous les titres d'anthropologue, d'ethnologue et de folkloriste. Pionnier dans l'avènement de l'ethnologie au Québec, il est également connu pour ses nombreuses enquêtes auprès de certaines tribus amérindiennes du Canada et de collectivités rurales du Québec. Ses travaux ont été l'objet de maintes études. Cependant, on semble oublier que ses recherches ont été menées sous le couvert du Musée national du Canada. Aussi, cet article se propose-t-il de faire connaître l'apport de Marius Barbeau à la muséologie au Québec et au Canada.

Afin de percevoir la contribution de cet ethnologue-folkloriste à la muséologie, il a été somme toute nécessaire de se replacer dans l'esprit du début du $\mathrm{xx}^{\mathrm{e}}$ siècle et de se demander en quoi Marius Barbeau incarne le muséologue contemporain à une époque où la profession n'était pas définie. Il s'agit, en d'autres mots, d'aborder de quelle manière Marius Barbeau a incarné le rôle de muséologue dans le sens contemporain du terme, et ce qui a fait de lui sans doute un modèle pour les générations futures de muséologues particulièrement au Québec, mais également au Canada. Avant tout, de brèves définitions seront ici relevées afin de cerner les termes de muséologie et de muséologue qui seront discutés tout au long de cet essai. Ensuite, à travers sa carrière et quelques-unes de ses réalisations, des éléments récurrents de sa pratique seront mis en relation avec la définition actuelle du muséologue et de son rôle dans les musées aujourd'hui.

\section{Musée, muséologie, muséologue}

D'abord, la muséologie a été définie par bien des spécialistes, de Rivière à 
Bazin, et débattue par l'ICOM à maintes reprises. Sa définition est multiple, devenant essentiellement l' « étude du musée ${ }^{1}$ » ou la « science du musée [qui] étudie [son] histoire et [son] rôle dans la société, les formes spécifiques de recherche [...] de conservation [...] de présentation, d'animation et de diffusion [de l'objet muséal], [ainsi que] d'organisation et de fonctionnement $[\ldots]^{2} \gg$ du musée, entre autres choses. De cette définition découle le « muséologue », une désignation encore peu employée parmi les professionnels du musée, mais qui est de plus en plus adoptée ${ }^{3}$. Au Québec, on applique généralement ce terme à toute la profession muséale, mais il est tout particulièrement employé pour désigner des professionnels liés à la conservation et à la mise en espace des collections ${ }^{4}$. Incarnant l'équilibre entre la théorie et la pratique, ce concept tend néanmoins à se séparer, donnant au musée la conservation et la diffusion de l'objet muséifié et à l'université (ou autres) l'étude du musée dans son historicité et son incidence dans la société ${ }^{5}$. On sépare ou on relie selon les décennies; on y met tantôt les collections, tantôt le public au centre de sa définition ${ }^{6}$.

\section{Marius Barbeau, conservateur}

Entre les années 1950 et 1980, la définition de la muséologie s'est modifiée et affinée au gré des sociétés, des besoins et des réflexions ${ }^{7}$. Quelques dizaines d'années auparavant, Marius Barbeau sort des bancs d'école, de l'Angleterre à la France, et obtient en 1911 un emploi d'assistant ethnologiste à la Commission géologique du Canada ${ }^{8}$. Auprès d'Edward Sapir, il travaille alors au nouveau département d'ethnologie dans le musée aménagé dans l'Édifice commémoratif Victoria (1910), qui ouvre ses portes au public la même année ${ }^{9}$. C'est sous le conseil d'un Canadien rencontré à

1. André Desvallées et François Mairesse, "Muséologie », Concepts clés de muséologie, sous la direction d'André Desvallées et de François Mairesse, Paris, Armand Colin, 2010, en ligne : $<$ http://icom.museum/fileadmin/user_upload/pdf/Key_Concepts_of_Museology/Museologie_Francais_ BD.pdf>, consulté le 8 février 2015.

2. Ibid.

3. André Desvallées et François Mairesse, «Sur la muséologie », Culture \& Musées, vol. 6, nº 6, 2005, p. 135.

4. André Desvallées et François Mairesse, « Muséologie », op. cit.; André Desvallées et François Mairesse, « Sur la muséologie », op. cit., p. 131.

5. Christine Bernier, L'Art au musée : de l'œeuvre à l'institution, Paris, L'Harmattan, 2002, p. 7-9 et $105-109$.

6. Germain Bazin, André Desvallées et Raymonde Moulin, « Muséologie », Encyclopaedia Universalis, en ligne : <http://www.universalis-edu.com.proxy.bibliotheques.uqam.ca:2048/ encyclopedie/ museologie>, consulté le 8 février 2015.

7. André Desvallées et François Mairesse, « Muséologie », op. cit. ; André Desvallées et François Mairesse, « Sur la muséologie », op. cit., p. 131-155.

8. Laurence Nowry, Man of Mana : Marius Barbeau, Toronto, NC Press Limited, 1995, p. 90.

9. Ibid., p. 91 ; Musée canadien de l'histoire, "À propos du musée : histoire du musée ", Musée canadien de l'histoire, http://www.museedelhistoire.ca/a-propos-du-musee/a-propos-du- 
Oxford, sir William Osler, que Barbeau se présente à la commission afin qu'il y introduise l'anthropologie, mais Sapir arrive en premier et Barbeau sera amené à monter les échelons ${ }^{10}$. Entreprenant ses enquêtes auprès des Hurons sous le conseil de Sapir, et des Iroquoiens peu de temps après, Barbeau obtient des promotions : d'ethnologiste associé à ethnologiste en $1922^{11}$. Dans les articles et communications, il est présenté comme un ethnologue du Musée Victoria, puis du Musée National du Canada (1927) ${ }^{12}$.

Son rôle, semble-t-il, au cours de sa carrière, répond à la définition actuelle du conservateur émise par l'ICOM : « Le conservateur(trice) est, sous l'autorité du directeur(trice), responsable des collections qui lui sont confiées. Ses fonctions se développent selon cinq axes : la conservation, l'enrichissement, l'étude, la valorisation et la gestion des collections du musée. ${ }^{13}$ » De ses nombreuses enquêtes, Barbeau rapporte en effet des objets afin d'enrichir les collections du musée ; il rapporte non seulement une culture matérielle, mais également immatérielle, soit des contes, des chansons et des savoirs qui viennent enrichir la collection. Il produit aussi des recherches et des fiches documentant chacune de ses observations sur le terrain permettant la documentation des objets ${ }^{14}$.

Comme plusieurs des premiers musées au Québec et au Canada, le Musée Victoria expose alors ses collections à la manière des cabinets de curiosités. Celles-ci sont alors entremêlées, exposées entre autres dans de grandes vitrines victoriennes et deviendront les prémisses de trois des quatre musées nationaux du Canada : le Musée canadien de la nature, le Musée des sciences et de la technologie du Canada, et bien entendu, le Musée canadien de l'histoire ${ }^{15}$. C'est dans ce contexte que Marius Barbeau se retrouve réalisant recherches et enquêtes, amassant, ou encore collectionnant ce qu'il peut, et surtout ce qui le passionnera : le « folklore». Précurseur des études universitaires en ethnologie, alors appelées « folklore », il prônera toute sa vie l'importance à la fois de la culture matérielle et immatérielle, alors que l'enseignement met en avant la culture immatérielle au détriment de

musee-2/histoire-du-musee, consulté le 8 février 2015.

10. Marius Barbeau (transcription par Renée Landry d'une entrevue réalisée en 1965 par Laurence Nowry), « Je suis un pionnier », Oracle, Ottawa, Musée national de l’Homme, n 43, 1982.

11. Laurence Nowry, op. cit., p. 90.

12. Archives du Musée canadien de l'histoire, Collection Marius Barbeau, Fonds Marius Barbeau, boîte B369, Dossier " Coupures de presse 1927 », f. 16 ; Archives du Musée canadien de l'histoire, Collection Marius Barbeau, Fonds Marius Barbeau, boîte B348, Dossier « Exposition - "Art du Vieux Québec"», f. 21.

13. Angelika Ruge, «Référentiel européen des professions muséales», Paris, Icom, 2008, p. 16, en ligne : <http://icom.museum/fileadmin/user_upload/pdf/professions/rererentieldesprofessions.pdf $>$, consulté le 8 février 2015.

14. Marius Barbeau, op. cit.

15. Musée canadien de l'histoire, op. cit. 
l'objet, et ceci jusque dans les années 1960 et $1970^{16}$. C'est finalement à cette époque que la culture matérielle refait son apparition et que les paroles et les convictions de Barbeau sont comprises dans leur totalité ; la culture matérielle ne prend, selon lui, sens qu'avec la culture immatérielle lui étant liée ${ }^{17}$.

Marius Barbeau incarne le conservateur dans toute sa splendeur. Il est le savant caricaturé par de nombreux auteurs, des Aventures de Tintin au Temps d'une paix, de haute stature et souvent représenté en plein travail, ce travail qui est l'œuvre de sa vie : une véritable vocation. Il est le représentant de la culture savante par son éducation et son statut ; il possède un réseau international de contacts avec lesquels il correspond tout au long de sa vie. Il continue son œuvre dans la tradition britannique, travaillant et écrivant en anglais tout en défendant la culture non seulement francophone, mais populaire : ses origines ${ }^{18}$. Cependant, Barbeau demeure une figure d'autorité qui voyage, étudie et écrit. Il est le conservateur, à la fois muséologue et muséographe, qui réalise la recherche, rédige les cartels et les catalogues d'exposition, choisit l'objet et le met en espace ${ }^{19}$. Barbeau rédige d'ailleurs deux de ses ouvrages, Québec où survit l'ancienne France et J'ai vu Québec, à la manière d'un catalogue d'exposition présentant des images d'objets et d'œuvres dans un certain ordre venant appuyer ou illustrer un discours qui lui est propre ${ }^{20}$. S'approchant de la tendance actuelle en muséologie du LAM (Librairies, Archives and Museums) ${ }^{21}$ typique des conservateurs contemporains, ses recherches, comme on le voit dans ses ouvrages, ne se cantonnent pas à étudier sa seule collection ${ }^{22}$. Il puise dans chacune des sources qui lui sont disponibles se riant d'une quelconque segmentation des genres, comme celle entre la culture dite « savante » et celle dite « populaire $»^{23}$. Il est aussi le conservateur-collectionneur, comme beaucoup avant lui dans les musées d'abord européens, puis américains. Dans une entrevue, il a d'ailleurs déclaré : «J'étais un collectionneur invétéré, toujours prêt à mettre la main

16. Yves Bergeron, « Naissance de l'ethnologie et émergence de la muséologie au Québec (19361945). De l'autre au soi », Rabaska : revue d'ethnologie de l'Amérique française, vol. 3, 2005, p. 22.

17. Ibid.

18. Paul Carpentier, «Marius Barbeau et le musée de l'Homme », Québec, Cap-aux-Diamants : la revue d'histoire du Québec, nº 25, 1991, p. 36-38 ; Yves Bergeron, op. cit., p. 20-22.

19. Andrew Nurse, « Tradition and Modernity : The Cultural Work of Marius Barbeau », thèse (Ph. D.) Philosophie, Kingston, Queen's University, 1997, p. 507-508.

20. Yves Bergeron, op. cit., p. 20 ; Marius Barbeau, Québec où survit l'ancienne France, Québec, Librairie Garneau limitée, 1937, 175 p. ; Marius Barbeau, J'ai vu Québec, Québec, Librairie Garneau limitée, 1957, s.p.

21. Sarah Higgins, « Digital Curating : the Challenge Driving Convergence across Memory Institutions », UNESCO, en ligne : http:/www.unesco.org/new/fileadmin/MULTIMEDIA/HQ/CI/CI/ pdf/ mow/VC_Higgins_27_D_1330.pdf(volonté de collaboration entre les institutions).

22. Marius Barbeau, J'ai vu Québec, op. cit. Remerciement.

23. Yves Bergeron, op. cit., p. 20-22. 
sur n'importe quoi, pour ainsi dire. C'était le cas à cette époque. Lorsque je commençais une collection dans un domaine, je n'arrêtais pas avant d'avoir fini. ${ }^{24} \gg$

Se désignant également comme « collectionneur-pionnier », il a introduit la culture populaire au sein même d'une institution savante ${ }^{25}$. Il ressent le besoin pressant de la sauvegarde de cette culture en perdition. Dans une entrevue accordée à Laurence Nowry réalisée en 1965, il dira : «Je vois avec grand plaisir et avec une immense satisfaction que le folklore, la linguistique et l'art populaire sont aujourd'hui acceptés au musée, qu'ils se trouvent au cœur même de son existence et de ses activités. Cet essor-là est certainement un produit de mon travail. J'ai ouvert la voie. ${ }^{26}{ }^{\prime}$ ”

Plus qu'un collectionneur et qu'un conservateur, Barbeau ressent le besoin de communiquer, de diffuser, de convaincre du fondement de ses observations, des résultats de ses recherches et des " merveilles » qu'il a découvertes. Alors que la tendance générale dépeint le conservateur dédié ultimement à sa collection et à son développement, Marius Barbeau semble se démarquer et devancer les idées qui seront discutées à Santiago en 1972 dans une rencontre organisée par l'UNESCO et, en 1974, à Copenhague dans une assemblée de l'ICOM $^{27}$. Cette idée est celle du musée comme institution « au service de la société et de son développement, ouverte au public ${ }^{28}$ », alors déjà mise de l'avant par Barbeau qui tend à rejoindre la majorité non seulement par des ouvrages découlant de ses recherches, mais aussi par des lectures, des cours, des conférences, des articles, des évènements et, bien entendu, des expositions ${ }^{29}$. Tentant d'instruire un maximum d'individus, il réussit à faire voyager plusieurs de ses projets; il convainc en effet le musée de faire de plusieurs de ses expositions des expositions itinérantes afin que le plus de monde possible puisse voir ce qu'il présente ${ }^{30}$.

\section{Marius Barbeau, diffuseur et commissaire : expositions et collections}

Outil de sa pensée

Barbeau est très présent dans les différentes tribunes, que ce soit les jour-

24. Marius Barbeau, « Je suis un pionnier », op. cit.

25. Frances M. Slaney, «Le Vitalisme dans l'anthropologie et l'art au Canada : la relation de Marius Barbeau aux peintres modernistes, particulièrement Emily Carr, au début du $\mathrm{xx}^{\mathrm{e}}$ siècle », The Journal of canadian Art History, $\mathrm{n}^{\circ}$ XXXI, 2010, p. 62-96.

26. Marius Barbeau, « Je suis un pionnier », op. cit.

27. Germain Bazin, André Desvallées et Raymonde Moulin, op. cit.

28. André Desvallées et François Mairesse, « Muséologie », op. cit.

29. Yves Bergeron, op. cit., p. 20 ; Archives du Musée canadien de l'histoire, Collection Marius Barbeau, Fonds Marius Barbeau, boîte B369, Dossier « Coupures de presse 1927 », f. 16 ; Archives du Musée canadien de l'histoire, Collection Marius Barbeau, Fonds Marius Barbeau, boîte B348, Dossier «Exposition - "Art du Vieux Québec" », f. 21.

30. Marius Barbeau, « Je suis un pionnier », op. cit. 
naux, la radio, et plus tard, la télévision. Toutes les tribunes sont bonnes à la transmission de ses idées passant d'une lecture au Canadian Woman's Press $C l u b$ à une conférence donnée pour le club des Arts et des lettres ${ }^{31}$. Même s'il n'apprécie pas particulièrement la radio et la télévision, croyant qu'elles corrompaient alors la pureté de la culture traditionnelle, il les utilisera néanmoins ${ }^{32}$.

Le musée, à l'instar des autres, apparaît comme l'un de ces outils qui permettent la diffusion de sa pensée. Sans être une finalité, il s'agit plutôt d'un prolongement de ses travaux de recherche et d'un moyen de diffuser ses idées à la manière d'un outil de communication. Persuasif, il réussit à organiser maintes expositions où son discours est à l'honneur ${ }^{33}$ et reste souvent le même : c'est dans la culture traditionnelle, matérielle ou immatérielle, que l'identité d'un peuple prend racine et se manifeste pour conserver et perpétuer ce qu'il est; il tend ainsi à montrer la valeur de l'art et de l'artisanat traditionnels ${ }^{34}$.

\section{Créateur de récit}

Tout au long de sa carrière, ses idées récurrentes prendront la forme d'ouvrages, d'expositions et de collections. Malgré une évidente nostalgie du passé, il prône que la culture est vivante et qu'elle n'est pas seulement de l'histoire ancienne. Elle se manifeste de fait dans les créations contemporaines et elle incarne un fil reliant toutes les manifestations de l'art, traditionnel ou savant, confondues ${ }^{35}$. Il affirmera que : « notre art moderne ne pourra se développer de façon originale si nos artistes, nos créateurs d'aujourd'hui ne connaissent pas leur folklore, leurs traditions. ${ }^{36}$ ». En d'autres mots, Barbeau mélange ancien et contemporain, populaire et savant, dans un tout continu qui forme la culture canadienne, ou encore l'identité canadienne, comme si aucune rupture n'avait eu lieu entre la société traditionnelle et l'arrivée de la modernité. Cette diffusion semble être un moyen de légitimer ses idées, de convaincre de l'importance qu'il accorde à ces objets (matériel et immatériel) à première vue opposés, mais qu'il relie dans une grande partie de ses manifestations. Il est ici créateur de récit, comme peut l'être le muséologue.

31. Archives du Musée canadien de l'histoire, Collection Marius Barbeau, Fonds Marius Barbeau, boîte B369, Dossier «Coupures de presse 1927 », f. 16. « Marius Barbeau at Press Club », Ottawa, The Citizen, 23 mars 1927.

32. Andrew Nurse, op. cit., p. 51.

33. Andrew Nurse, op. cit., p. 344.

34. Yves Bergeron, op. cit., p. 21-22 ; Andrew Nurse, op. cit., p. 507-508 et 596.

35. Frances M. Slaney, op. cit., p. 77.

36. Marius Barbeau, « Je suis un pionnier », op. cit. 
Alors que par ses cours et ses discours, à l'University of British Colombia ou à l'Université Laval, il a fait reconnaitre le folklore au sein des universités, c'est par ses expositions qu'il semble avoir convaincu les jeunes institutions muséales de l'époque, mais particulièrement le public, de l'intérêt pour son passé ${ }^{37}$.

L'exposition, The Exhibition of Canadian West Coast Art, native and modern, présentée à la Galerie nationale (Ottawa), à la Art Gallery de Toronto en 1927 et à la Montreal Art Association en 1928, et réalisée en collaboration avec le Musée national, présentait ses idées en faisant dialoguer des objets ethnologiques de tribus de l'Ouest avec des œuvres du Groupe des Sept, de Paul Kane, et en grand nombre, d'Emily Carr ${ }^{38}$. Étant le principal instigateur, il crée ici un discours qui est le sien avec des objets manifestement hétéroclites, tout en étant liés, les mettant sur un pied d'égalité artistique et montrant l'inspiration qu'octroient les premiers aux seconds ${ }^{39}$. Comme il est possible de remarquer dans les journaux de l'époque, il accompagne l'exposition et discourt à la fois sur l'importance vitale de l'art pour les Amérindiens de l'Ouest tout en insérant dans son propos les principes impliqués dans le développement d'un art national ${ }^{40}$. Montrant la qualité des objets par son exposition, il rappelle l'imminence de leurs disparitions par un oubli généralisé et, par le fait même, une mise de côté du passé ${ }^{41}$.

Une visite d'une délégation française à l'occasion du quatrième centenaire de l'arrivée de Jacques Cartier (1934) a mené le Musée national (ou Musée Victoria) de l'époque à organiser au dernier moment une exposition de quelques semaines installée dans la grande rotonde de l'établissement ${ }^{42}$. C'est naturellement Marius Barbeau qui obtient le mandat d'élaborer l'exposition ayant alors pour thème l'artisanat des Canadiens français ou plus précisément des Québécois. L'exposition, intitulée Handicrafts of Old

37. Leslie Dawn, « Cross-Border Trading: Mungo Martin Carves for World of Tomorrow », $B C$ Studies, p. 11. C.f. http://ojs.library.ubc.ca/index.php/bcstudies/article/view/577/620 ; Yves Bergeron, op. cit., p. 21-22.

38. Archives du Musée canadien de l'histoire, Collection Marius Barbeau, Fonds Marius Barbeau, boîte B348, Dossier « Exhibition of Canadian West Coast Art - Native and Modern », f. 14. Marius Barbeau, « West Coast Indian Art », Exhibition of Canadian West Coast Art, native and modern [brochure], Ottawa, The National Gallery of Canada, décembre 1927, p. 3-4 ; Frances M. Slaney, op. cit., p. 77.

39. Frances M. Slaney, op. cit., p. 77 et 98.

40. Archives du Musée canadien de l'histoire, Collection Marius Barbeau, Fonds Marius Barbeau, boîte B369, Dossier « Coupures de presse 1928 », f. 17. « Art of Western Indian Reviewed : Carving, Painting and Vocal Abilities of Native Stressed by M. Barbeau », Montréal, The Gazette, 18 février 1928 ; Ibid., "Art Was a Necessity Among the Indians of The Pacific Coast », Montréal, The Montreal Daily Star, 18 février 1928.

41. Andrew Nurse, op. cit., p. 410-412.

42. Archives du Musée canadien de 1'histoire, Collection Marius Barbeau, Fonds Marius Barbeau, boîte B348, Dossier « Exposition - "Art du Vieux Québec" », f. 21. « Les Arts du terroir au Musée Victoria », Ottawa, Le Droit, 18 septembre 1934. 
Québec (L'artisanat du vieux Québec), présentait des objets provenant de divers travaux d'artisanat, tels que des couvrepieds « boutonnus » et des sculptures sur bois, dans la rotonde toujours ponctuée de mâts totémiques ${ }^{43}$. Selon le journal Le Droit de l'époque, Barbeau a su transformer « artistiquement » le lieu en salle d'exposition ${ }^{44}$. Ce dernier mentionne d'ailleurs aux délégués français que la province de Québec a non seulement conservé ses sculptures et ses tissages de la France, mais également les vieilles chansons françaises disparues pour la majorité de leur pays d'origine ${ }^{45}$. Cette exposition montée pour l'évènement a encore permis ici à Barbeau de transmettre ses recherches et d'exposer le folklore.

Il développe sa pensée une nouvelle fois lorsqu'il est invité à sélectionner les objets représentant l'artisanat canadien du Pavillon canadien à l'Exposition universelle de Paris en 1937. Collaborant avec le regroupement The Canadian Handicrafts Guild, Barbeau choisit des objets qui sont sensiblement les mêmes que les objets présentés dans les précédentes expositions : des sculptures sur bois, des travaux de tissage, etc. Ces objets sont ainsi installés dans des vitrines accrochées sur un seul mur du pavillon de 55 pieds de longueur ${ }^{46}$. Il s'agit une nouvelle fois d'une opportunité que Barbeau a su attraper afin d'instruire et de montrer au plus grand nombre la culture populaire du Canada, particulièrement québécoise. Il sait d'ailleurs habilement convaincre ou tenter de persuader ses prêteurs, comme c'est le cas de la supérieure de l'Hôpital-Général de Québec. Dans une lettre de demande de prêt, il mentionne en effet : « Je me souviens que l'année dernière le Cardinal, lors de son passage en France, faisait un discours où il annonçait que le Canada ferait connaître ses anciennes chansons françaises et les arts et métiers, à l'Exposition universelle. S'il était nécessaire d'obtenir son autorisation, je suis sûr qu'il ne manquerait pas de la donner ${ }^{47} »$. Barbeau montre ainsi son désir de présenter certains objets plus que d'autres, toujours afin de présenter un même patrimoine, celui qu'il connaît et qu'il maîtrise.

Marius Barbeau a par ailleurs participé à un grand nombre d'expositions et d'évènements semblables qui ne peuvent être traités ici. Un dernier exem-

43. Archives du Musée canadien de l'histoire, Collection Marius Barbeau, Fonds Marius Barbeau, boîte B348, Dossier «Exposition - "Art du Vieux Québec" », f. 21. « La France salue le Canada avec ferveur », Ottawa, Le Droit, 4 septembre 1934 ; Ibid., "Special Exhibit In National Museum "Handicrafts of Old Quebec" Now on View in Main Floor Lobby », Ottawa, The Citizen, 8 septembre 1934.

44. Ibid., « La France salue le Canada avec ferveur », Ottawa, Le Droit, 4 septembre 1934.

45. Ibid.

46. Frances M. Slaney, op. cit., p. 77 ; Archives du Musée canadien de l'histoire, Collection Marius Barbeau, Fonds Marius Barbeau, boîte B349, Dossier « Exposition de Paris 1937 », f. 6. Compte rendu d'une conférence tenue le $1^{\text {er }}$ mars 1937.

47. Archives du Musée canadien de l'histoire, Collection Marius Barbeau, Fonds Marius Barbeau, boîte B349, Dossier « Exposition de Paris 1937 », f. 6. Lettre du 24 mars 1937 de Marius Barbeau à la Révérende Mère Supérieure de l'Hôpital-Général de Québec. 
ple suffira : l'exposition rétrospective, plus imposante que prévu, de l'œuvre de Cornelius Krieghoff en $1934^{48}$. Fasciné par l'œuvre de ce dernier, Marius Barbeau reprend les œuvres et quelques écrits sur la vie du peintre afin de les diffuser à l'aide de différents médias (articles, expositions, catalogue, etc. $)^{49}$. Krieghoff devient rapidement le modèle idéal reflétant la pensée de Barbeau ; il est l'artiste qui, en s'inspirant de la culture populaire, a su créer un art véritablement canadien, mariant ainsi à merveille à la fois la culture savante et la culture traditionnelle ${ }^{50}$. Peintre d'un passé oublié, cet artiste et son œuvre respirent, selon l'ethnologue-folkloriste, l'authenticité et le reflet de son époque. Idéalisant et romançant quelque peu son histoire, son œuvre et son engagement, Barbeau a donné à Krieghoff, par l'itinérance de son exposition, de ses catalogues, de son enseignement et de ses nombreux écrits, une place significative dans l'histoire de l'art canadien qui n'est aujourd'hui plus ignorée, et ceci malgré les fortes critiques à l'encontre de l'artiste et du maître d'œuvre ${ }^{51}$.

Le muséologue est créateur de récit, non seulement dans l'élaboration d'expositions, mais également dans la constitution de collections. Tout au long de sa carrière, plusieurs institutions ont fait appel à lui afin d'enrichir ou de constituer leurs collections ${ }^{52}$. La Maison commémorative de sir Wilfrid Laurier à Saint-Lin est un exemple indiscutable de la vision d'un Québec traditionnel de Marius Barbeau. Selon ses mémoires, la Commission des parcs nationaux lui laisse alors « le soin de l'aménager avec discernement et d'en faire un monument national à sa mémoire ${ }^{53} »$. En plus de former la collection de cette maison patrimoniale, il élabore la mise en exposition des objets non seulement acquis, mais aussi commandés. En effet, Barbeau achète et fait produire des objets auprès d'artistes, dont Arthur Lismer, et d'artisans de sa connaissance afin de meubler la maison faisant de celle-ci un témoin de sa propre pensée ${ }^{54}$. En ce sens, la Maison Laurier devient pratiquement une œuvre totale de la pensée de Barbeau : de son idéalisation d'un Canada français tout droit sorti du passé. Il est en outre intéressant à mentionner que d'autres collections, dont celle du Fort Chambly, du Musée

48. Andrew Nurse, op. cit., p. 344-345.

49. Ibid., p. 362-364.

50. Ibid.

51. Ibid., p. 344-346, 363-366 et 371-393.

52. Marius Barbeau, « Je suis un pionnier », op. cit.

53. Archives du Musée canadien de l'histoire, Collection Marius Barbeau, Fonds Carmen Roy, boîte 624, Dossier « "Les Mémoires de Marius Barbeau”. (Transcription textuelle d'entrevue), 1957-58 », f. 12 , p. 156.

54. Archives du Musée canadien de l'histoire, Collection Marius Barbeau, Fonds Marius Barbeau, boîte 70, Dossier « Maison Laurier, St-Lin (1939-1940) », f. 20 ; Archives du Musée canadien de l'histoire, Collection Marius Barbeau, Fonds Marius Barbeau, boîte 70, Dossier « Maison Laurier Barbeau souvenir », f. 20. Extrait d'un texte rapportant les souvenirs de Marius Barbeau sur la Maison Laurier. 
McCord et du Musée royal de l'Ontario, ont également réclamé ponctuellement ses services ${ }^{55}$.

\section{Conclusion}

Au Deuxième congrès de la langue française de 1937, $\mathrm{M}^{\text {gr }}$ Olivier Maurault, alors recteur de l'Université de Montréal, avait dit : « Il nous faut une culture $^{56} \gg$. Marius Barbeau semble l'avoir compris bien avant et l'avoir pris au mot bien après. Chacune de ses recherches, de ses expositions et de ses prises de parole semble teintée de son désir de donner ou de rendre compte d'une culture propre aux Canadiens. Il incarne le muséologue contemporain qui réalise des recherches et des expositions, qui acquiert et conserve des objets et des traces d'un passé révolu, mais toujours présent dans les créations artistiques de son époque. Son passage semble de plus avoir marqué, non seulement les professionnels dans son sillage immédiat et ceux qui viendront après, mais également les institutions muséales québécoises. Barbeau fera ainsi du musée un lieu d'affirmation d'une culture où la culture savante se mélange à la culture populaire, et où l'objet matériel et immatériel complète le casse-tête d'une mémoire collective, d'une culture commune et d'un musée au service de la société.

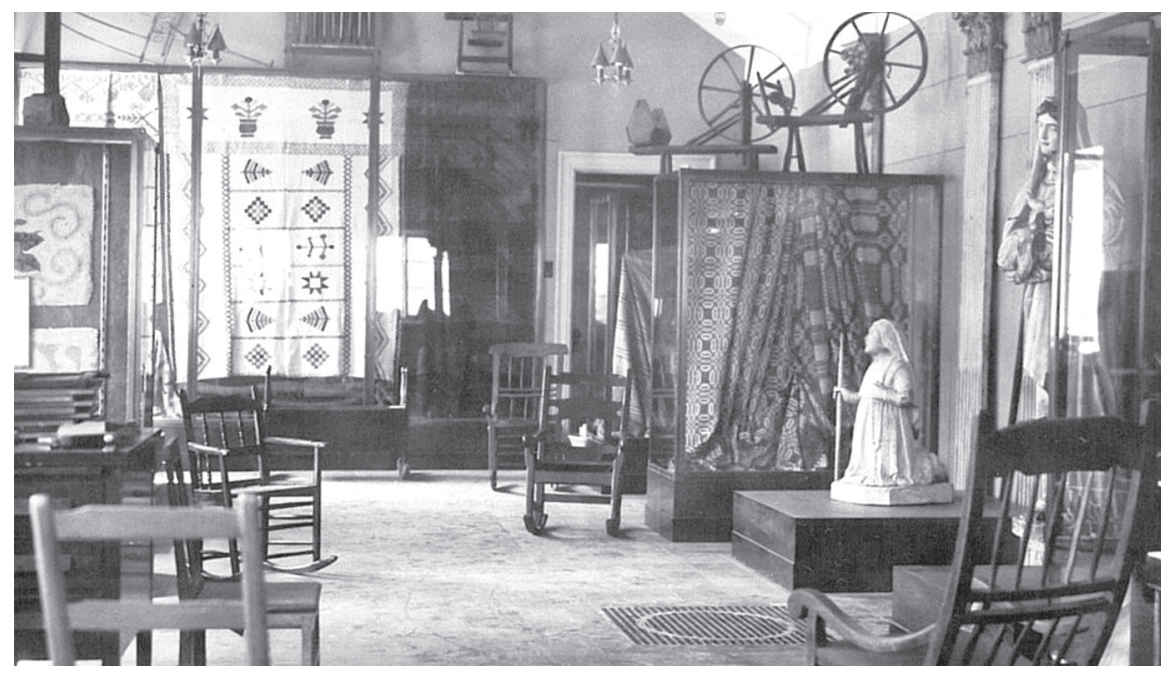

Intérieur du Musée du fort Chambly montrant un ensemble de pièces choisies par Marius Barbeau en 1936.

Source : Musée canadien de l'histoire no B563-3.3.

55. Andrew Nurse, op. cit., p. 323.

56. $\mathrm{M}^{\mathrm{gr}}$ Olivier Maurault, « Le Rôle de la culture française dans la vie canadienne. $-\mathrm{M}^{\text {gr }}$ Olivier Maurault, P.S.S., P.D., Recteur de 1'Université de Montréal », dans Deuxième congrès de la langue française au Canada, Québec, 27 juin - $1^{\text {er }}$ juillet 1937 : compte rendu, Québec, Imprimerie de L'Action Catholique, 1938, p. 211. 